\title{
Hepato-morpholoy and biochemical studies on the liver of albino rats after exposure to glyphosate-Roundup ${ }^{\oplus}$
}

\author{
Shaimaa M. M. Saleh ${ }^{1 *} \mathbb{D}$, Tasneem A. Elghareeb ${ }^{2 \dagger}$, Mohamed A. I. Ahmed ${ }^{2+}$, Ibrahim A. Mohamed ${ }^{2 \dagger}$
} and Hosam A. Ezz El-Din² ${ }^{2+}$

\begin{abstract}
Background: The object of this work was to evaluate of the hepatic effects of the herbicides glyphosate-Roundup ${ }^{\oplus}$ by different doses in both sexes of albino rats.

Methods: Forty animals divided into four groups with ten animals for each (both sexes) were treated orally with vehicle (controls) and 25, 50, and $100 \mathrm{mg} / \mathrm{kg}$ bwt of glyphosate-Roundup (treated groups) for 15 days daily.

Results: The most conspicuous changes occurred on the liver treated groups due to glyphosate toxicity were the increase of enzymes activities of ALT and AST, cellular infiltration, many signs of nucleus degeneration, focal necrosis, rarified cytoplasm, disorganization of cellular organelles, and deposition of lipid droplets. The increase in the amount of collagenous fibers and the number of the mast cell were also observed.
\end{abstract}

Conclusion: Our results indicated that the administration of glyphosate-Roundup in different doses may cause adverse effects on the histopathological, ultrastructure, and biochemical alternations on the liver of the albino rats.

Keywords: Glyphosate-Roundup ${ }^{\oplus}$, ALT and AST, Liver, Histopathology, Ultrastructure

\section{Background}

Glyphosate [N-(phosphonomethyl) glycine] (GLP) is an organophosphorated non-selective agrochemical used widely in a lot of countries, such as Turkey, and after the sprout, it acts in a systemic way (WHO (World Health Organization) 1994). In 1974, the agricultural company, Monsanto, was developed and commercialized GLP in a formulation marketed as Roundup (Guyton et al. 2015). GLP shows lower level of toxicity for animals and a lower mobility in comparison to other pesticides (Gasnier et al. 2009) and environmental friend lines (Franz et al. 1997). It is perhaps the most important herbicide ever developed (WHO (World Health Organization) 1994).

GLP is used in commercial formulations, which include other chemical additives (including surfactant) that enhance its efficiency as a weed killer, by promoting toxicity

\footnotetext{
* Correspondence: omjasminejory@yahoo.com

${ }^{\dagger}$ Tasneem A. Elghareeb, Mohamed A. I. Ahmed, Ibrahim A. Mohamed and Hosam A. Ezz El-Din contributed equally to this work.

'Department of Zoology, Faculty of Science, Assiut University, Assiut 71516, Egypt Full list of author information is available at the end of the article
}

and improving the plant's ability to take up the herbicide (Vincent and Davidson 2015 and Defarge et al. 2016). It has a low permanence and because of employment of this herbicide for prevailing of weeds in agricultural fields, large quantities find their way into water bodies. The random use of the herbicide therefore makes it a potential source of danger to animals, not only in grazing fields but also in the water bodies (Ayoola 2008).

Glyphosate metabolites into aminomethyl phosphoric acid (AMPA) and formaldehyde are found as a contaminant in environments such as soil and rivers (WHO (World Health Organization) 1994). Two possible metabolic pathways for GLP in the human body lead eventually to formaldehyde. Six different enzymes that have the capability to catalyze the conversion of formaldehyde to formic acid is present in animal tissue (Swanson et al. 2016). It is known that formic acid has the ability to cause the malfunction of metabolic acidosis and mitochondria (Kruse 1992). EFSA (European Food Safety Authority) (2015) reported that about $20 \%$ of ingested glyphosate is absorbed from the gastrointestinal tract, and according to US EPA 
(U.S. Environmental Protection Agency) (2006), the figure is $30-36 \%$. The absorbed portion is spread widely in the bone, kidneys, and liver with highest concentrations.

Roundup causes inhibition of enzymes implicated in the detoxification of chemicals in the body (Acquavella et al. 2004). GLP have negative effects on some number of enzymes in the CYP (cytochrome P450) superfamily (McLaughlin et al. 2008) located in cell mitochondria and microsomes which play a main function in the liver (Gasnier et al. 2009).

There was a controversy about safety and toxicity of glyphosate. On the one hand, it is considered as a safe compound (Vereecken 2005) since it has not been bioaccumulated, biomagnified, or preserved in a biologically available form in the environment (Helander et al. 2012). Recent work has shown that both glyphosate and AMPA were eliminated slowly from the plasma. On the other hand, although the bioavailability of glyphosate and AMPA was only $23.21 \%$, it is likely that GLP is distributed through the body by the blood's circulation and there may be considerable diffusion of it into tissues to exert systemic effects (Anadón et al. 2009). Myers et al. (2016) reported that metabolism studies strongly point to bioaccumulation in the kidney and liver.

Gasnier et al. 2009reported that GLP was used for a period of time as the minimal harmful herbicides, while recent studies display that GLP can get many risks and not be as safe as conceptualized before (Franz et al. 1997). The present study represents an effort to identify the effects of different doses of GLP for a short period of time on the liver of adult albino rats.

\section{Methods}

\section{Experimental design}

This study was performed to investigate the effects of different doses of glyphosate on rats. Forty adult male and female albino rats were organized into four groups of ten individuals each (both sexes). The first group (M1 and F1) served as a control received vehicle. The second group (M2 and F2) of animals was treated with $25 \mathrm{mg} / \mathrm{kg}$ bwt of glyphosate. The third group (M3 and F3) of animals was treated with $50 \mathrm{mg} / \mathrm{kg}$ bwt of glyphosate. The fourth group (M4 and F4) of animals was treated with $100 \mathrm{mg} / \mathrm{kg}$ bwt of glyphosate. The herbicide in all treated groups diluted in distilled water and was administered orally, by gavage, on a daily basis for a period of 15 days. Collections of blood and hepatic tissue were made at the end of this period of time.

\section{Materials}

Chemicals

Roundup (glyphosate 48\% WSC Monsanto Co.) was obtained from the Central Agricultural Pestiscide Laboratory (CAPL) in Dokki, Giza, Egypt.

\section{Animals}

Male and virgin female albino rats (90-day-old, 129-230 g) were bought from the Assiut University Joint Animal Breeding, Assiut, Egypt. All rats kept under the same laboratory conditions of temperature (25 \pm 2$)$ lighting (12:12 light-dark cycle) and were given free access to standard food and tap water. They were allowed to acclimatize for 3 weeks before experiments. The experiment was approved by the Ethics Committee of Assiut University, Egypt.
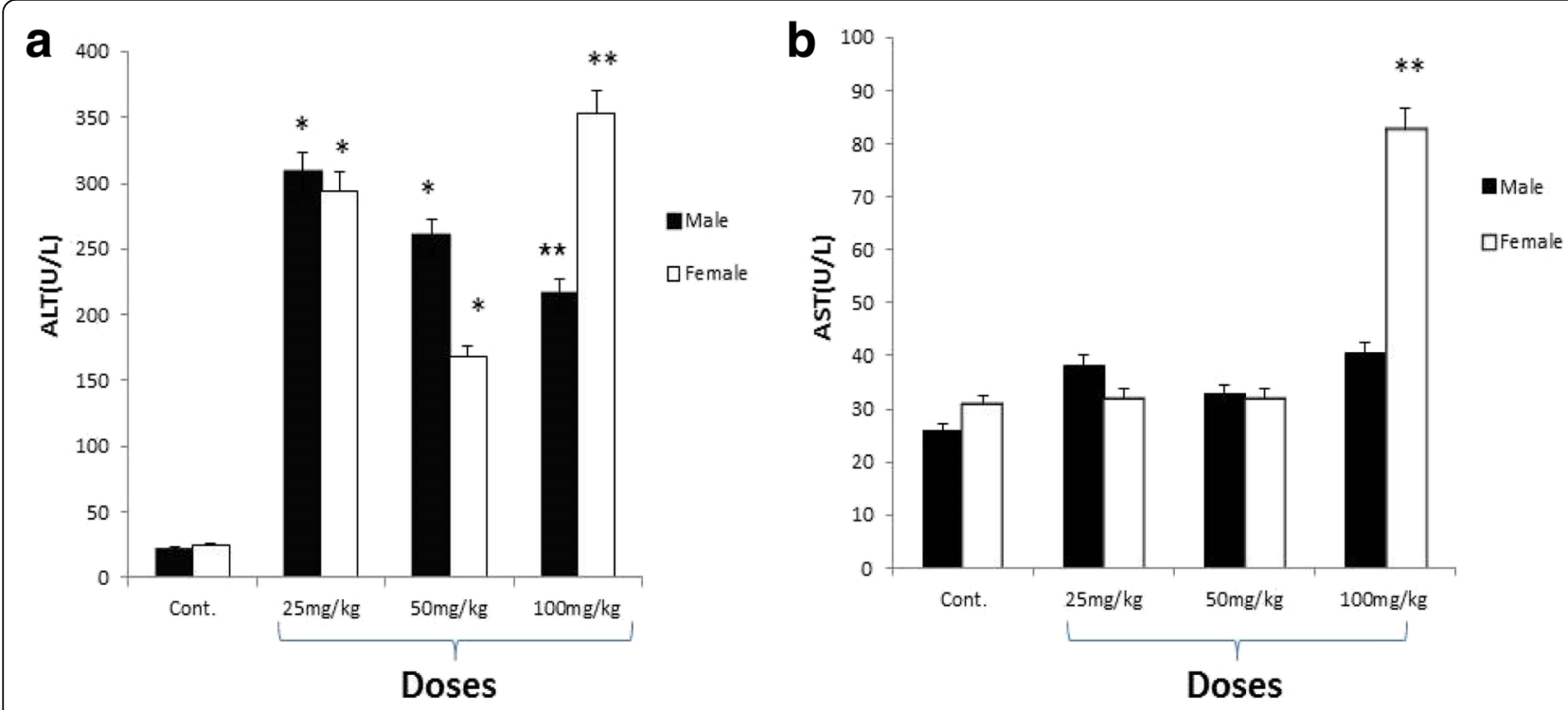

Fig. $1 \mathbf{a}$ and $\mathbf{b}$ Values of treated groups with respect to control are significantly differing at: ${ }^{*} P<0.05$, ${ }^{* *} P<0.01$ 


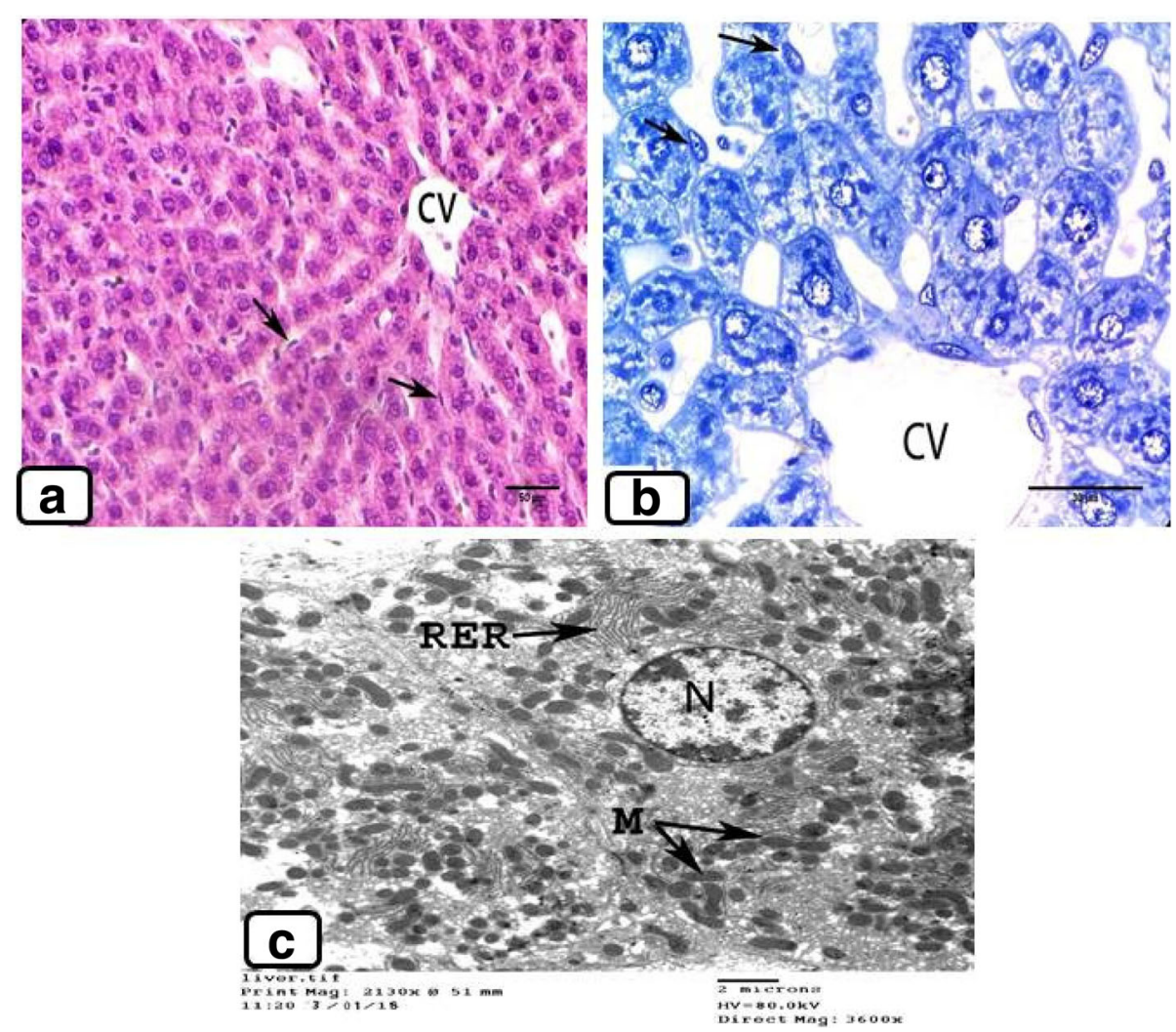

Fig. 2 a Liver section of control rat showing normal polyhedral hepatocytes radiating from the central vein (CV) with eosinophilic cytoplasm and centrally located nuclei. The blood sinusoids are often seen with phagocytic Kupffer cells (arrows) between the cords of hepatocytes (H\&E). b Semithin section of control rat liver showing the normal structure of hepatocytes and central vein (CV). Note: Kupffer cells (arrows) (toluidine blue stain). $\mathbf{c}$ Electron micrograph of the hepatocyte of control rat showing centrally located rounded nucleus (N), normal distribution of hetero and euchromatin, well-developed rough endoplasmic reticulum (RER), and mitochondria with dense matrices and vary in shape (M)

\section{Experimental procedures}

\section{Measurements of liver enzymes in serum}

Blood samples were collected from orbital sinus of all animals immediately before animals were killed. Serum was separated by centrifugations at $3000 \mathrm{rpm}$ for $10 \mathrm{~min}$. The serum was used for liver function assessment employing measurements of the enzymes alanine aminotransferase (ALT) and alanine aspartate aminotransferase (AST) by following the instructions of enzymatic colorimetric assay kits (Diamond Diagnostic).

\section{Histopathological experiments}

Liver samples were taken from all animals by surgical processing after the animal was killed. All samples were kept in formal alcohol for $24 \mathrm{~h}$. Blocks were made following standard methods. Sections were cut 5-7 $\mu \mathrm{m}$ thick, stained with hematoxylin and eosin according to Drury and Wallington (1980). These sections were investigated under light microscopy.

\section{Transmission electron microscopy study}

Immediately after sacrificing the animals, small specimens were taken from the liver and fixed in 5\% cold glutaraldehyde for $24 \mathrm{~h}$; the specimens were then washed in three to four changes of cacodylate buffer $(\mathrm{pH}$ 7.2) for $20 \mathrm{~min}$ in each change and postfixed in cold osmium tetraoxide for $2 \mathrm{~h}$. Thereafter, the specimens were washed in four changes of cacodylate buffer for $20 \mathrm{~min}$ each. Dehydration was carried out using ascending grades of ethyl alcohol of 30,50, and 70\%, each for $2 \mathrm{~h}$, and two changes of 90 and $100 \%$ for 30 min each. Embedding was carried out in Epon 812. The embedded samples were kept in an incubator at $35{ }^{\circ} \mathrm{C}$ for 1 day, at $45{ }^{\circ} \mathrm{C}$ for another day, and at $60{ }^{\circ} \mathrm{C}$ for 3 days (Woods and Stirling, 2008).

Semithin sections of $0.5-1 \mu \mathrm{m}$ were prepared using an LKB ultramicrotome, Germany. The sections were stained with toluidine blue, examined with a light microscope, and photographed. Ultrathin sections (50-80 nm) from selected areas of the trimmed blocks were taken 

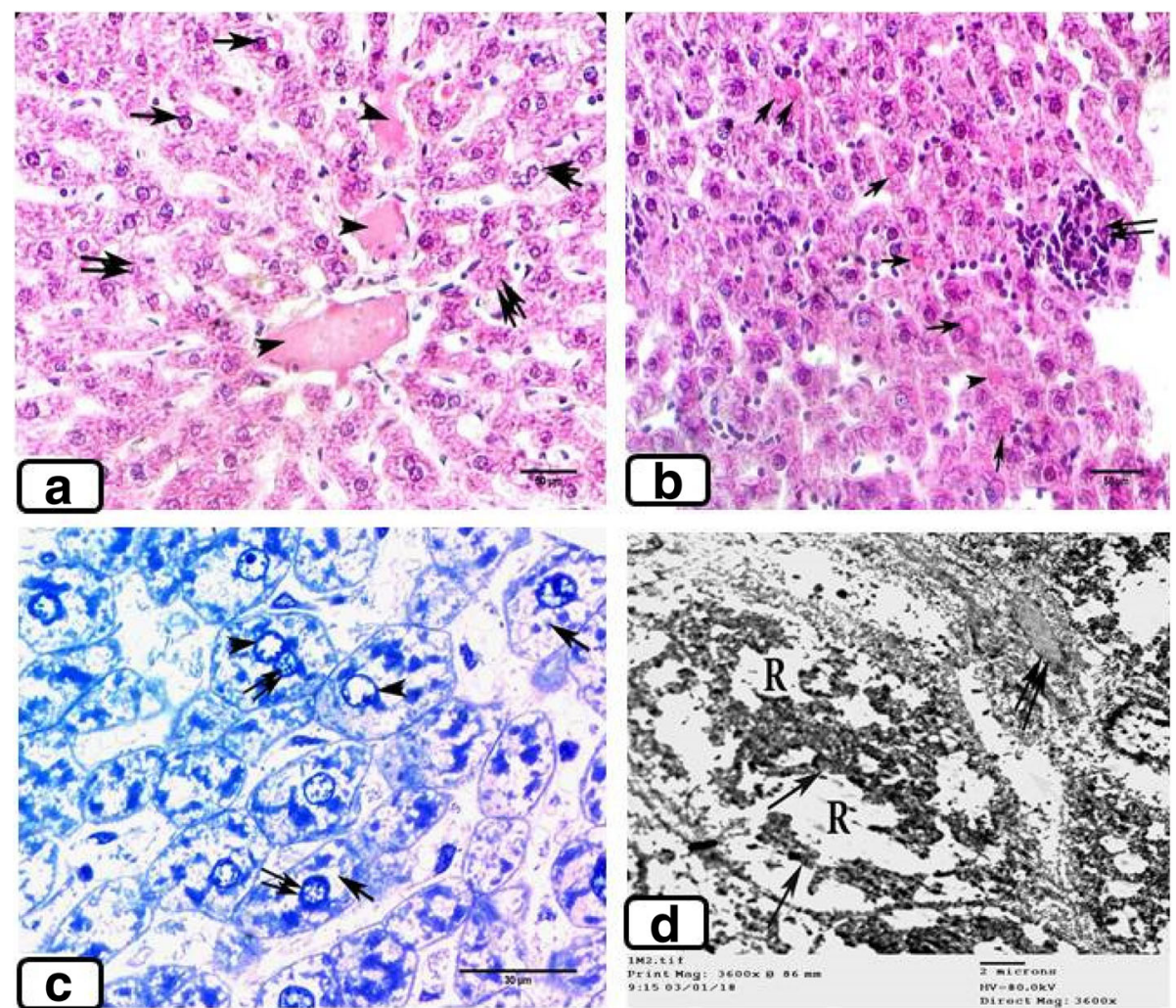

Fig. $3 \mathrm{M} 2$ group liver showing a vacuolated cytoplasm with deeply stained nuclei $(\uparrow)$, degeneration of some hepatocytes ( $\uparrow$ ), and congestion of blood vessels and central vein (arrowhead) (H\&E). Note: the Kupffer cell puched into the sinusoids lumen. $\mathbf{b}$ Eosinophilic stain (red color) of nuclei $(\uparrow)$, leucocytic aggregation between hepatocytes $(\uparrow \uparrow$ ), degeneration of many hepatocytes (arrowhead), and other hepatocytes with vacuolated cytoplasm and pyknotic nuclei (H\&E). c Vacuolated cytoplasm of many hepatocytes $(\uparrow)$ with deeply stained nuclei ( $\uparrow$ ) and the nucleoplasm of some nuclei devoid chromatin (arrowhead) (toluidine blue). $\mathbf{d}$ Ultrastructure of hepatocytes showing many rarified areas in the cytoplasm (R) and disorganization and dissociation of cellular organelles (necrosis) ( $\uparrow$ ). Note: collagenous fibers between hepatocytes $(\uparrow \uparrow$ )

and collected on a copper grid. The ultrathin sections were contrasted with uranyl acetate for $10 \mathrm{~min}$ and with lead citrate for $5 \mathrm{~min}$, examined by transmission electron microscopy (JEOL 100 CX; JEOL, Japan), and photographed at $80 \mathrm{kV}$ in the Assiut University Electron Microscopy Unit.

\section{Statistical analysis}

The quantitative results of the present work were expressed as means \pm SEM. Differences between means were tested by one-way analysis of variance (ANOVA) followed by the student-Newman-Keul $t$ test and were considered different with respect to control data at two levels of significance: ${ }^{*} P<0.05$ and ${ }^{* *} P<0.01$.

\section{Results}

\section{Biochemical study}

Hepatotoxicity was detected by quantitative analysis of the serum ALT and AST activities, which were used as the biochemical markers of liver damage as showed in Fig. 1. The result showed that the higher dose results in higher level of enzyme activities exposed to glyphosate. There was a significant difference in ALT enzymes activities between glyphosate-treated groups and controls (Fig. 1a). While AST activity in treated groups showed an increase but insignificant difference between glyphosate-treated groups and controls. However, F3 group showed high significantly difference $(p<0.01)$ compared to treated groups and controls (Fig. 1b).

\section{Morphology}

A normal liver structure was observed in the control animals (M1 and F1) as shown in Fig. 2a, b. Electron microscope examination revealed that the liver showed normal appearance of hepatocytes with centrally placed prominent nuclei and cytoplasm that contained a large number of mitochondria and rough endoplasmic reticulum (RER) (Fig. 2c).

In the present study, many cellular changes on the hepatic tissue of all treated groups compared to controls were evident. In male rats group that received $25 \mathrm{mg}$ / $\mathrm{kg}$ bwt of glyphosate (M2), it showed obvious histopathological changes in the form of hepatocyte cordon plan disarrangement in parenchymal cells due to dilatation of blood sinusoids. Damage of the wall of the blood 


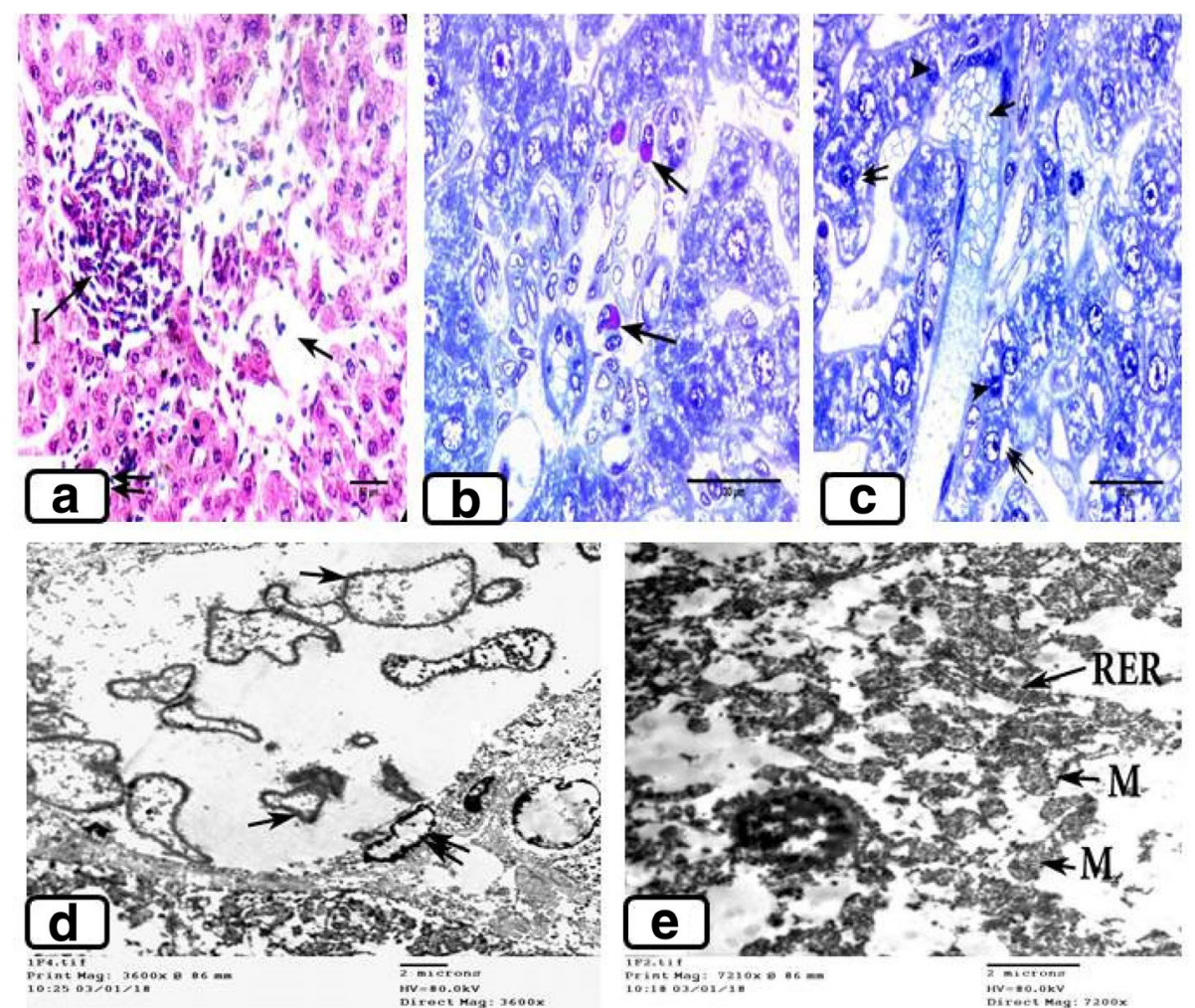

Fig. 4 F2 group liver showing a focal necrotic area ( $\uparrow$ ), foci of cellular infiltration around the portal area (I), leucocytic aggregation between liver cells $(\uparrow \uparrow)$, and vacuolation and degeneration of many hepatocytes (H\&E). $\mathbf{b}$ Many of mast cells between portal areas ( $\uparrow$ ) (toluidine blue stain). $\mathbf{c}$ Large dilatation of blood sinusoids filled with deformed RBCs $(\uparrow)$, highly vacuolated cytoplasm of many hepatocytes ( $\uparrow \uparrow$ ), and pyknotic nuclei (arrowhead). Note: deposition of RBCs debris in the wall of blood sinusoids (toluidine blue stain). $\mathbf{d}$ Ultrastructure of hepatocytes showing deformed RBCs with thickened their plasma membrane $(\uparrow)$ and the nuclei of endothelial cell appeared irregular in shape with condensed chromatin ( $\uparrow$ ). e Ultrastructure of hepatocytes showing destructed mitochondria $(M)$ and fragmented rough endoplasmic reticulum (RER). Note: degenerated nuclei

vessel and blood sinusoid was observed (Fig. 3a). Other signs of degeneration were reflected by small leucocytic aggregation among the liver cells and unusual red color stain (eosinophilic stain) of the nuclei was prominent (Fig. 3b). Semithin sections revealed highly vacuolated cytoplasm of some hepatocytes. In the binucleated hepatocytes, one appeared deeply stained while other nuclei chromatin may be aggregated in their inner membrane or the chromatin were disintegrated; the nucleoplasm devoid from chromatin and appeared empty (Fig. 3c). Ultrastructural investigation in male rats received $25 \mathrm{mg} / \mathrm{kg}$ bwt revealed significant changes compared to control group. The cellular organelles of the liver cell showed disorganization and dissociation (necrosis). Moreover, the amount of collagenous fibers in-between hepatocyte was detected (Fig. 3d).

Examination of the liver sections of female rats after administration of $25 \mathrm{mg} / \mathrm{kg}$ of glyphosate (F2) showed some of the similar changes to those observed in male rats administered with $25 \mathrm{mg} / \mathrm{kg}$ (M2). However, additional remarkable histopathological changes were represented by large foci of necrotic area and also increase the amount of cellular infiltration around the portal area (large foci) compared to M2 group (Fig. 4a). Toluidine blue examinations revealed few of mast cells between portal areas (Fig. 4b). Also, vacuolation and aggregation of cell organoids in many hepatocytic cytoplasms were observed (Fig. 4b, c). The blood sinusoids appeared more widening and congested with deformed RBCs (Fig. 4c, d). The RBCss plasma membrane was thick and the nuclei of endothelial cell is irregular in its shape and with condensed chromatin (Fig. 4d). Moreover, the damage and destruction of mitochondria and the remaining of fragmented RER were obvious (Fig. 4e).

The male rats that received $50 \mathrm{mg} / \mathrm{kg}$ bwt of glyphosate (M3) showed bilirubin pigments (yellow materials) in blood vessels, blood sinusoids, and between liver cells (Fig. 5a). Marked extensive necrosis of large area of hepatocytes with dispersion of all their contents and areas devoid of hepatocytes associated with hemorrhage was detected (Fig. 5b). Moreover, polyploidy nuclei (red and blue color) of many hepatocytes were prominent in many liver sections. Also, most of the liver cells degenerated and vacuolated. Sometimes, lipofuscin pigment (yellow-brown color) filled the macrophage cells (Kupffer cells) of the liver tissue (Fig. 5c). 


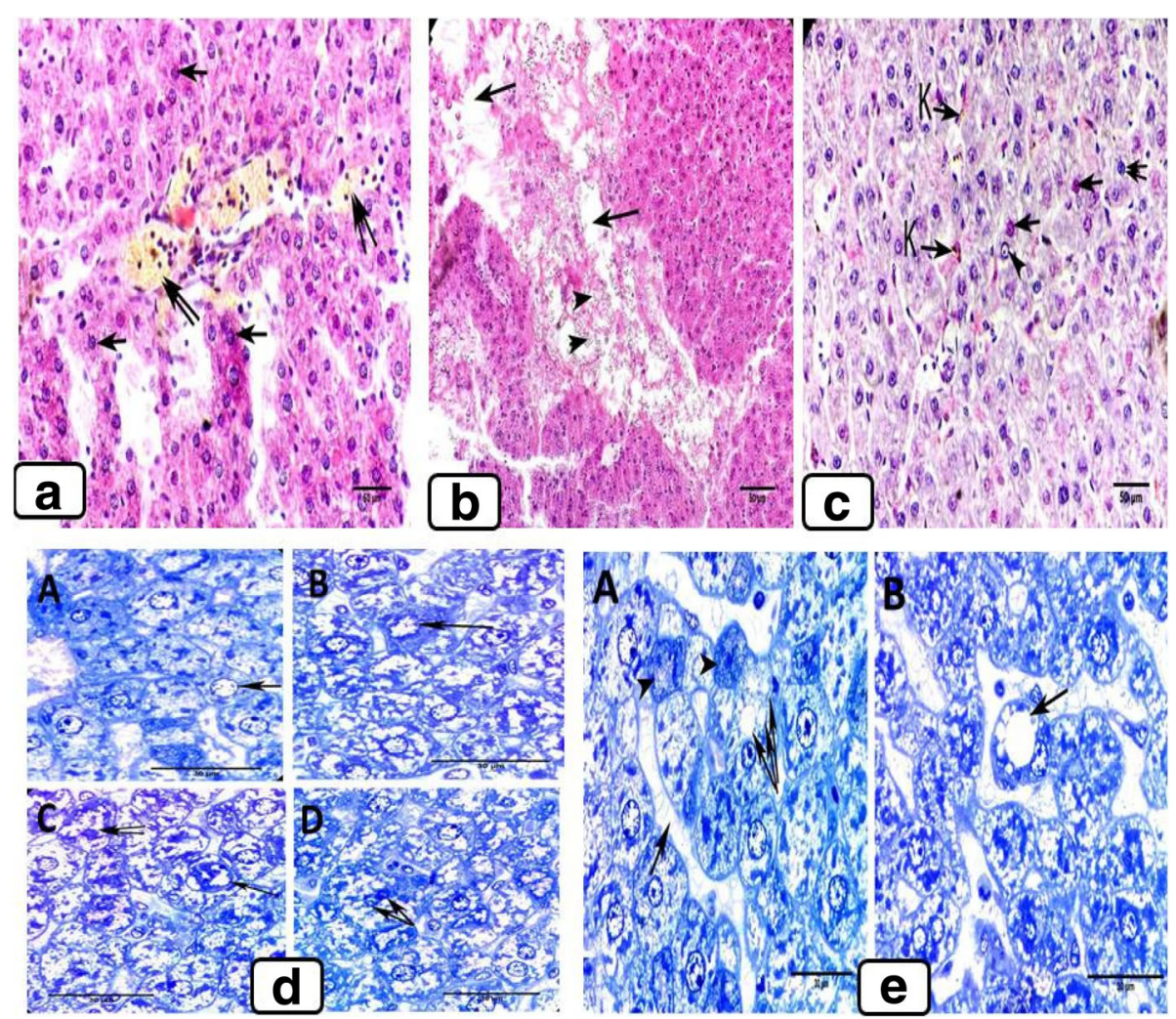

Fig. 5 M3 group liver showing a many necrotic areas (n), bilirubin filled the blood sinusoid and between hepatocytes ( $\uparrow$ ), degeneration of most of the hepatocytes and small dark stain nuclei was observed ( $\uparrow$ (H\&E). b Marked extensive necrosis of large area of hepatocytes with dispersion of their contents and areas devoid of hepatocytes ( $\uparrow$ ). Note: RBCs in the destructed area (hemorrhage) (arrowhead) (H\&E). c Polyploid nuclei (red and blue color) $(\uparrow)$, chromatin of few nuclei segregation in their inner membrane and appeared empty (arrowhead) and other hepatocytes with small dark stained nuclei ( $\uparrow \uparrow$ ). Notice lipofuscin pigments (yellow-brown color) in few Kupffer cells (K) (H\&E). d $A$ nuclei showed chromatolysis, $B$ Irregular shape of nuclei, $C$ nuclei enlarged in size with clumped of their chromatin and $D$ hypertrophic of binucleated hepatocytes with pyknotic nuclei (toluidine blue stain). e A Hepatocyte with many of vacuoles differed in size ( $\uparrow$ ), apoptotic cells (arrowhead), and dilated and congested blood sinusoids with a thickened wall $(\uparrow)$. B Hepatocyte contains large vacuole (toluidine blue stain)

Different liver sections in toluidine blue-stain semithin sections of the M3 group revealed many pathological changes in the nuclei of hepatocytes. The nuclei sometimes showed segregation of euchromatin in their inner membrane or chromatolysis (nucleoplasm depleted from chromatin) and appeared empty (Fig. 5d (A)), while in other hepatocytes, the nuclei appeared irregular in shape (Fig. $5 \mathrm{~d}$ (B)), enlarged in size, and clumped of their chromatin (Fig. 5d (C)) and pyknosis in hypertrophic binucleated hepatocyte (Fig. 5d (D)). In other liver sections, many hepatocytes showed vacuolation and others with many vacuoles different in size (Fig. 5e (A, B)), and many of the apoptotic cells were detected (Fig. 5e (A)). Dilatation and congestion of blood sinusoids were filled by abnormally shaped RBCs; their plasma membrane appeared thick. Moreover, apoptotic cell was also observed (Fig. 6a). Other affected hepatocytes with pyknotic nuclei and large parts of cytoplasm depleted from cellular organelles (Fig. 6b).

Histological investigation of female rats taking $50 \mathrm{mg} /$ $\mathrm{kg}$ bwt of glyphosate (F3) revealed lesion of most hepatocytes and huge focal leucocytic aggregation with deposition of amount of fibers was prominent (Fig. 6c). Other changes appeared more or less similar to the M3 group. Electron microscopic investigation of this group revealed hepatocyte with large lipid droplet between the fragmented RER and other organelles (Fig. 6d). In other severe hepatocytes, activated mast cell was detected and its nuclei has condensed chromatin. Many of the collagenous fibers between liver cells were observed (Fig. 6e).

In male rats administered with $100 \mathrm{mg} / \mathrm{kg}$ bwt, many histopathological changes were revealed. In binucleated hepatocytes, the nuclei were dissimilar in color stain and disintegration in most cytoplasmic contents (Fig. 7a). An increase in the number of Kupffer cells was noticed. Many of them were filled with lipofuscin pigments (Fig. 7b). Fusions of the lumen of both congested blood vessels and blood sinusoid were detected due to the disruption of their walls, and most of the hepatocytes had extensive vacuolar degeneration (Fig. 7c). In severe hepatocytes, the fragmentation of cell organelles forming 


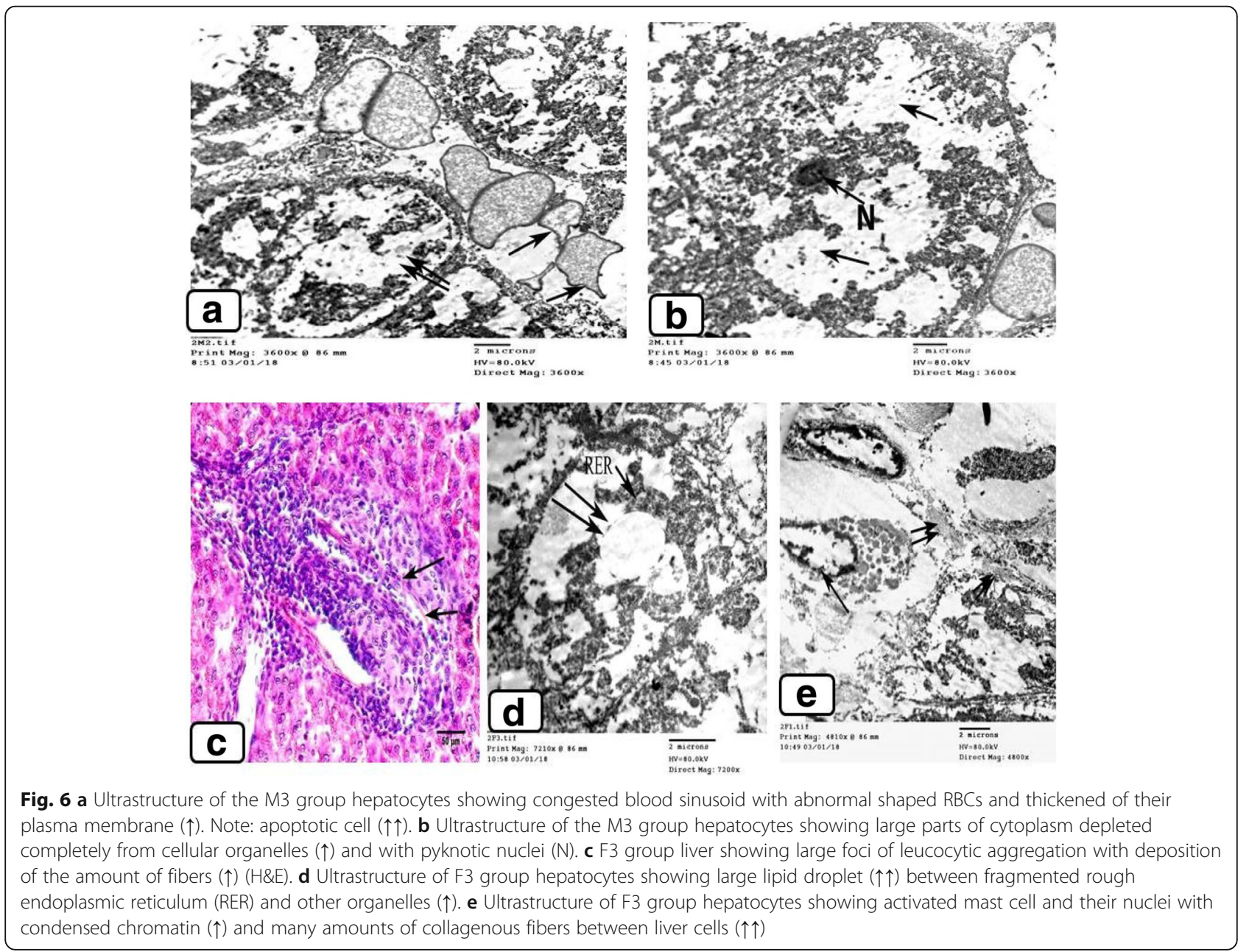

electron dense clusters and the remaining of the fragments of RER were observed (Fig. 7d).

In female rats groups that were administered with $100 \mathrm{mg} / \mathrm{kg}$ glyphosate (F4), a large necrotic area with hemorrhage and cellular infiltration was obvious (Fig. 8a). Toluidine blue stained sections revealed an increase in pathological changes compared to previously treated groups and appear more or less similar to the M4 group (treated with $100 \mathrm{mg} / \mathrm{kg}$ ). These changes represented by an increase in the widening of blood sinusoids and damage of their walls led to the fusion of their lumens which filled with RBCs (Fig. 8b (A, B)), and the nuclei of some hepatocytes showed karyolysis and many hepatocytes depleted from the cytoplasm (Fig. 8b (B)). Hepatic ultrastructural alternation revealed the abnormal appearance of three nuclei in one cell, one of them showed their nuclear membrane was damaged, the other one showed a separation between their inner and outer membrane, while the last one appears degenerated (Fig. 8c, d).

\section{Discussion}

Based on the results of the present study, glyphosate-Roundup causes biochemical and histopathological changes in the liver of both sexes of treated groups. These changes were more intensified in the case of high dose (100 mg/kg but) used in our study duration.

Statistically, the levels of AST and ALT enzymes showed an increase in the serum of treated groups compared to those of controls in the present study after 15 days of exposure to GLP. This observation is in line with Benedetti et al. (2004) who demonstrated an increase in the levels of the enzymes ALT and AST that causes cellular alterations. These alternations were represented by an increase of connective tissue and deposition of collagen in hepatocytes of Wistar rats exposed to glyphosate-Biocarb ${ }^{\circ}$.

Large deposition of collagenous fibers may cause modifications in the diffusions of solutes, like proteins, between the hepatocytes and plasma. This may induce liver cells dysfunction (Pratt and Kaplan 2001). Jyothi and Narayan (1999) 

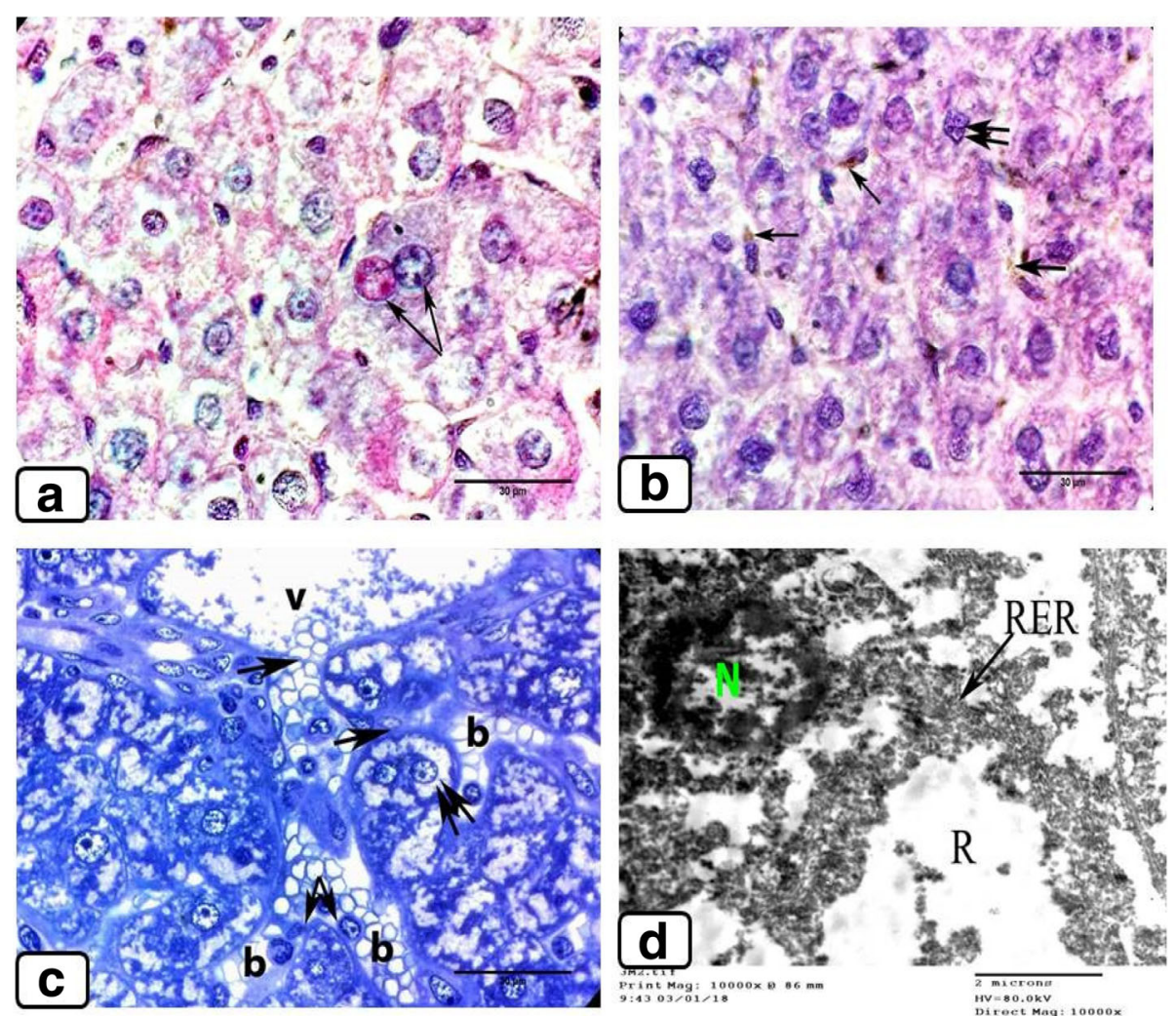

Fig. 7 M4 group liver showing a binucleated hepatocytes were dissimilar in their color stain ( $\uparrow$ ) and most of the hepatocytes devoid completely from the cytoplasm (H\&E). $\mathbf{b}$ Yellow-brown color of lipofuscin pigments in many of Kupffer cells $(\uparrow)$ and the nuclei of some hepatocytes appeared irregular in its shape $(\uparrow \uparrow)(H \& E)$. c Damage of the wall of both blood vessels $(V)$ and blood sinusoids $(b)$ and fusion of their congested lumen ( $\uparrow$ ) and most hepatocytes with extensive vacuolar degeneration ( $\uparrow$ ) (toluidine blue stain). $\mathbf{d}$ Ultrastructurally of hepatocyte showing remaining of fragment RER ( $\uparrow$ ) rarified cytoplasmic space $(\mathrm{R})$ and degenerated nucleus $(\mathrm{N})$

suggested that damages of the liver may cause the production of mitochondrial enzymes like alkaline phosphatase which was thinly released into the blood. The toxic effects could be lipolytic in nature, as a result of which the cell membrane, lysosomal membrane, and other organelles underwent dissolution, releasing the enzymes through blood. Hence, the increased plasma enzyme activities in the present investigation may be a result of cell necrosis in the liver.

Histological investigations revealed many alternations. These alternations were in the form of disarrangement in parenchymal cells, mononuclear cell infiltration, many apoptotic hepatocytes, and many focal necrotic areas. Also, an increase in the number of Kupffer cells with deposition of lipofuscin pigments and the amount of collagenous fibers was noticeable.

In the present investigation, a remarkable collection of inflammatory cells adjacent to some blood vessels and invading the hepatic tissue were observed after administration of glyphosate. A similar result was reported by Caglar and Kolankaya (2008) and EFSA (European Food Safety Authority) (2015) in the rat liver. Wunderlich et al. (2005) suggested that the abundance of leucocytes in general and lymphocyte in particular is a prominent response of body tissues facing injurious impact. Also, Trasher et al. (1988) reported that formaldehyde (which is one of the metabolites of glyphosate) might be conjugated with human serum albumin and yield a new antigen. This antigen encouraged the body to manufacture anti-formaldehyde human serum antibodies and raise the antigen memory cells. This led to sustained stimulation of the immune system.

Our study indicates cellular degeneration followed by necrosis, especially after $100 \mathrm{mg} / \mathrm{kg}$ but dose of glyphosate. Similar findings were obtained in juvenile African catfish (Clarias gariepinus) exposed to glyphosate (Ayoola 2008). Also, Cox (1995) and Jashni et al. (2013) found that glyphosate causes damage and overgrowth in the renal cells in the female albino rat. Moreover, Caglar and Kolankaya (2008) reported focal necrosis and some of the apoptotic hepatocytes on rats after exposure to glyphosate-based herbicide Roundup.

John et al. (2001) suggested that organophosphorus including glyphosate produce free radicals in the cells that cause structural changes in cell proteins and unsaturated lipid peroxidation in the cells. These complications can cause cell necrosis and neoplastic changes. Biagiant- 

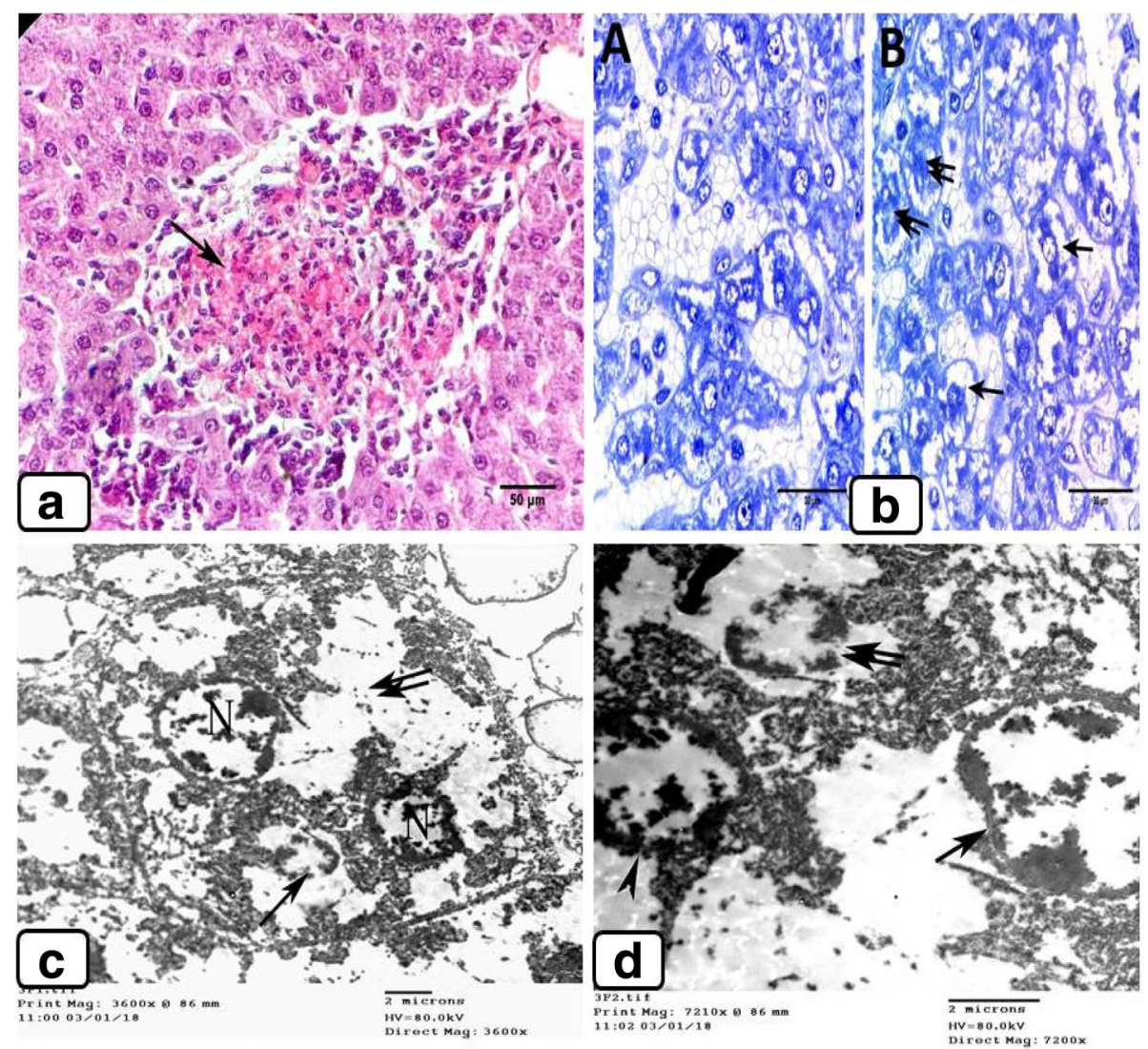

Fig. 8 F4 group liver showing a large necrotic area with leucocytic aggregation and hemorrhage (H\&E). b F4 group liver showing A congested blood sinusoids and damage of their walls led to the fusion of their lumens (toluidine blue stain). B Most cells depleted from the cytoplasm ( $\uparrow$ ) and degeneration of most of the nuclei $(\uparrow \uparrow)$ (toluidine blue stain). $\mathbf{c}$ Ultrastructure of hepatocytes showing three degenerated nuclei ( $\mathrm{N}$ ); one of them their nuclear membrane was damaged $(\uparrow)$. Large empty spaces due to the destruction of most cell organoids ( $\uparrow$ ). $\mathbf{d}$ Ultrastructure of hepatocytes showing three nuclei, one of them their nuclear membrane was damaged $(\uparrow \uparrow)$, the other one showed separation between their inner and outer membrane $(\uparrow)$ while the last one appears degenerated (arrowhead)

Risbourg and Bastide (1995) explain the necrosis of some portions of the liver tissue that were observed probably resulted from the excessive work and needs to dispose of the toxicant from its body during the process of detoxification by the liver.

The present study revealed that Kupffer cells increased in number and sometimes filled with lipofuscin pigments after glyphosate administration. These results agree with EFSA (European Food Safety Authority) 2015who found diffuse acute inflammation in the liver with pigment deposits in rats. Also, Benedetti et al. (2004) and Caglar and Kolankaya (2008) indicated that after higher doses of glyphosate, the Kupffer cells in hepatic sinusoids were increased.

Benedetti et al. (2004) illustrated that the infiltration of Kupffer cells was followed by large deposition of reticular fibers, mononuclear cell infiltration, and congestion of the liver tissues. They also reported that these could have contributed to the weakness of regular liver function due to xenobiotic modification in detoxification processes.
Curran (1987) explained that lipofuscin granules and residual bodies, which represent the indigestible remnants of cell organelles and cytoplasmic materials, increased in cases of increasing age or the presence of a wasting disease, the condition of brown atrophy results. In this case, death followed prolonged cachexia (weakness and wasting of the body due to severe chronic illness) caused by malignant disease.

It is evident from the present study that the administration of glyphosate resulted in distinctive subcellular alterations in hepatocytes. Glyphosate administration induced rarified cytoplasm, disorganization of cellular organelles, and deposition of lipid droplets. In addition, the presence of activated mast cells between the portal areas and the increase of collagenous fibers also were observed.

The deposition of lipid droplets and vacuolization on hepatocytes of rats exposed to GLP were observed in the present study and were reported by Biagiant- Risbourg and Bastide (1995), who found that fish atrazine liver display an increased in the lipid droplets size and 
vacuolization after exposure to herbicide. Also, they were reported by Samanta et al. (2016) who found excess of fat deposition in liver fish (Heteropneustes fossilis). The presence of sufficient number of lipid droplets suggested a decay in the synthesis of protein in the cytoplasm (which involved in transport triglycerides and serve as lipid metabolizing enzymes) which ultimately blocks the utilization of lipid-protein conjugation (Cheville 1994). In this case, the lipids are continuously produced at a normal rate, which leads to progressive accumulation of lipid globules (Holm et al. 1993). Liver cells vacuolization perhaps illustrate an imbalance between the average synthesis of substances in the parenchymal cells and the rate of their release into the systemic circulation (Gingerich 1982).

In the present investigation, the nucleus showed a depletion from chromatin and the nucleoplasm appeared empty and sometimes, a very few amount of chromatin aggregate in the inner nuclear membrane. So, this may illustrate the changes of the nucleus from blue to red color in the present study and this is maybe due to that chromatin is known to give the nucleus its basophilic stain. Gasnier et al. 2009) and Mañas et al. (2009) reported injury of DNA in human hepatocytes with 50\% DNA strand breaks after exposure to GLP and Roundup. Also, Cutler (2010) added that the damage of DNA in the liver cells can foster that cell death and possibly create a cancerous cell. These previous reports may illustrate that the chromatins became decays and the nucleoplasm appeared empty in some cells and appeared red in others.

The mast cell can be recognized by its content of metachromatic granules when appropriately fixed and stained with metachromatic dyes such as toluidine blue. It is implicated in neoplastic, immunological, inflammatory, and other conditions (Yong 1997). Based on the ultrastructure appearance of mast cells positive granules, morphological sings of activation of many of the mast cells were distinguished in our present study. Those positive granules of mast cell when appeared and invigorate in liver play a critical role in the adjustment of the fibrogenesis and inflammation. This inflammation and fibrogenesis were known to cause dangerous damage to the liver as nonspecific reactive hepatitis (Gulubova et al. 2005).

\section{Conclusion}

From the present study, it may be concluded that glyphosate induced biochemical, histopathological, and subcellular alterations in hepatocytes of liver structure in male and female rats. Results from this investigation may contribute to the understanding of the effect(s) of different doses and simultaneous exposition to glyphosate on cell survival, and they may be of clinical interest in the evaluation of the degree of damage to which humans are involuntarily exposed due to environmental pollution.
Our findings suggest that we should be very careful during use of glyphosate as an herbicide in our fields and that we should use it in a specific dose according to WHO to reduce as much as possible its passive effects. We should also overcome the problems resulting from eating food may contain glyphosate. Taking a good antioxidant to strengthen our immune system can provide one of the possible remedies.

\section{Abbreviations \\ ALT: Alanine aminotransferase; AST: Alanine aspartate aminotransferase; GLP: Glyphosate; RER: Rough endoplasmic reticulum; US EPA: US \\ Environmental Protection Agency; WHO: World Health Organization}

\section{Acknowledgements}

We acknowledge the support of the Zoology Department, Assiut University, Egypt.

\section{Funding}

Funding for this study was provided by the authors.

\section{Availability of data and materials}

Rats purchased from Assiut University Joint Animal Breeding, Assiut, Egypt, and the kits purchased from the specific producing company. GlyphosateRoundup was obtained from Central Agricultural Pesticide Laboratory (CAPL) in Dokki, Giza, Egypt. All data are available from the corresponding author upon request.

\section{Authors' contributions}

Dr. SSHMM designed the experiment, practical work, histological analysis, carried out the biochemical data analysis, and wrote the manuscript. ELTA contributed to the practical work. Dr. IMA contributed his idea of work. Dr. MIA and Prof. EHA contributed by providing the chemicals. All authors read and approved the final manuscript.

\section{Ethics approval and consent to participate}

This study was carried out in accordance with the ethical rules for handling the experimental animals, Zoology Department, Faculty of Science, Assiut University, Egypt.

\section{Consent for publication}

No human subjects are included. No individual person's data are included.

\section{Competing interests}

The authors declare that they have no competing interests.

\section{Publisher's Note}

Springer Nature remains neutral with regard to jurisdictional claims in published maps and institutional affiliations.

\section{Author details}

'Department of Zoology, Faculty of Science, Assiut University, Assiut 71516, Egypt. 2Plant protection Department, Faculty of Agriculture, Assiut University, Assiut 71526, Egypt.

Received: 15 August 2018 Accepted: 24 October 2018

Published online: 16 November 2018

\footnotetext{
References

Acquavella, J. F., Alexander, B. H., Mandel, J. S., Gustin, C., Baker, B., Chapman, P., \& Bleeke, M. (2004). Glyphosate biomonitoring for farmers and their families: results from the farm family exposure study. Environmental Health Perspectives, 112(3), 321-326. https://doi.org/10.1289/ehp.6667.

Anadón, A., Martínez-Larrañaga, M. R., Martínez, M. A., Castellano, V. J., Martínez, M., Martin, M. T., Bernal, J. L. (2009). Toxicokinetics of glyphosate and its metabolite aminomethyl phosphonic acid in rats. Toxicology Letters, 190(1), 91-95. https://doi.org/10.1016/j.toxlet.2009.07.008.

Ayoola, S. O. (2008). Histopathological effects of glyphosate on juvenile African catfish (Clarias gariepinus). American-Eurasian Journal Of Agricultural \& Environmental Sciences, 4(3), 362-367 https://www.researchgate.net/ publication/237539217.
} 
Benedetti, A. L., Vituri, C., Trentin, A. G., Domingues, M. A. C., \& Alvarez-Silva, M. (2004). The effects of sub-chronic exposure of Wistar rats to the herbicide glyphosate-biocarb. Toxicology Letters, 153, 227-232. https://doi.org/10.1016/j. toxlet.2004.04.008.

Biagiant- Risbourg, S. B., \& Bastide, J. (1995). Hepatic perturbations induced by a herbicide (atrazine) in juvenile grey mullet Liza ramada (Mugilidae: Telostei): An ultrastructural study. Aquatic Toxicology, 31, 217-229 https://doi.org/10. 1016/0166-445X(94)00065-X.

Caglar, S., \& Kolankaya, D. (2008). The effect of sub-acute and sub-chronic exposure of rats to the glyphosate-based herbicide Roundup. Environmental Toxicology and Pharmacology, 25, 57-62. https://doi.org/10.1016/j.etap.2007. 08.011.

Cheville, N. F. (1994). Ultrastructural pathology: an introduction to interpretation, (first ed., ). Ames: lowa State University Press.

Cox, C. (1995). Glyphosate, part 1: Toxicology. Journal of Pesticide Reform, 15(3), 1-27 http://www.inspiringlandscapes.com/hope/glyphos8.htm.

Curran, R.C., (1987). Colour atlas of histology, Third edition. English Language Book Society/Harvey miller/Oxford University Press. ISBN: 0194424200 and 9780194424202

Cutler, N. (2010). Sodium benzoate: Reducing Sod's Harm to liver. http:// webcache.googleusercontent.com/search?q=cache:wTRKMLDeitgJ:https:// www.liversupport.com/sodium-benzoate-reducing-sodas-harm-to-the

Defarge, N., Takács, E., Lozano, V. L., Mesnage, R., de Vendômois, J. S., Séralini, G., \& Székács, A. (2016). Co-Formulants in Glyphosate-Based Herbicides Disrupt Aromatase Activity in Human Cells below Toxic Levels. International Journal of Environmental Research and Public Health, 13(3), 264 https://doi.org/10. 3390/ijerph13030264.

Drury, R. A. B., \& Wallington, E. A. (1980). Carleton's histological technique, (5th ed., ). Oxford, New York, Tortonto: Oxford University Press.

EFSA (European Food Safety Authority). (2015). Final addendum to the Renewal Assessment Report public version. Risk assessment provided by the rapporteur Member State Germany and co-rapporteur Member State Slovakia for the active substance GLYPHOSATE according to the procedure for the renewal of the inclusion of a second group of active substances in Annex I to Council Directive 91/414/EEC laid down in Commission Regulation (EU) No. 1141/2010. October 2011. https://corporateeurope.org/ food-and-agriculture/2015/11/efsa-and-member-states-vs-iarc-glyphosate-hasscience-won

Franz, J. E., Mao, M. K., \& Sikorski, J. A. (1997). Glyphosate: A Unique Global Herbicide (pp. 521-527-604-605, 615). Washington, DC: American Chemical Society.

Gasnier, C., Dumont, C., Benachour, N., Clair, E., Chagnon, M. C., \& Séralini, G.-E. (2009). Glyphosate-based herbicides are toxic and endocrine disruptors in human cell lines. Toxicology, 262, 184-191 DOI: 10.101 G/j .tox.2009.0G.006

Gingerich, W. H. (1982). Hepatic toxicology of fishes. In L. J. Weber (Ed.), Aquatic Toxicology, (pp. 55-105). New York: Raven Press. https://doi.org/10.1080/ 01926230590890187

Gulubova, M., Vlaykova, T., Kalinova, K., Vodenicharov, A., VaSilev, I., \& Velev, V. (2005). Liver tryptase-positive mast cell and fibrosis in children with hepatic echinococcosis. Journal of Indian Association of Pediatric Surgeons, 10, 237243. https://doi.org/10.4103/0971-9261.19273.

Guyton, K. Z., Loomois, D., Grosse, Y., El Ghissassi, F., Benbrahim-Tallaa, L., Guha, N. Straif, K. (2015). Carcinogenicity of tetrachlorvinphos, parathion, malathion, diazinon, and glyphosate. The Lancet Oncology, 16(5), 490-491 https://doi. org/10.1016/S1470-2045(15)70134-8.

Helander, M., Saloniemi, I., \& Saikkonen, K. (2012). Glyphosate in northern ecosystems. Trends in Plant Science, 17(10), 569-574. https://doi.org/10.1016/j. tplants.2012.05.008.

Holm, G., Norrgren, L., Andresson, T., \& Thuren, A. (1993). Effects of exposure to food contaminated with PBDE, PCN or PCB on reproduction, liver morphology and cytochrome P450 activity in the three-spined stickleback, Gasterosteus aculeatus. Aquatic Toxicology, 27, 33-50 https://doi.org/10.1016/ 0166-445X(93)90045-3.

Jashni, K. H., Novin, L., \& Ahmadi, P. M. (2013). Effect of the herbicide glyphosate on renal tissues in adult female rats. Journal of Jahrom University of Medical Sciences, 11(4), 9-16. https://doi.org/10.29252/jmj.11.4.2.

John, S., Kale, M., Rathore, N., \& Bhatnagar, D. (2001). Protective effect of vitamin E in dimethoate and malathion induced oxidative stress in rat erythrocytes. The Journal of Nutritional Biochemistry, 12(9), 500-504 https://doi.org/10.1016/ S0955-2863(01)00160-7.
Jyothi, B., \& Narayan, G. (1999). Certain pesticide-induced carbohydrate metabolic disorders in the serum of freshwater fish Clarias batrachus (Linn.). Food and Chemical Toxicology, 37, 417-421 https://doi.org/10.1016/S0278-6915(99)00020-4. Kruse, J. A. (1992). Methanol poisoning. Intensive Care Medicine, 18, 391-397.

Mañas, F., Peralta, L., Raviolo, J., Garcia, O. H., Weyers, A., Ugnia, L., Gorla, N. (2009). Genotoxicity of glyphosate assessed by the comet assay and cytogenic tests. Environmental Toxicology and Pharmacology, 28, 37-41. https://doi.org/10. 1016/j.etap.2009.02.001.

McLaughlin, L. J., Dickmann, L. J., Wolf, C. R., \& Henderson, C. J. (2008). Functional expression and comparative characterization of nine murine cytochromes P450 by fluorescent inhibition screening. Drug Metabolism and Disposition, 36(7), 1322-1331. https://doi.org/10.1124/dmd.108.021261.

Myers, J. P., Antoniou, M. N., Blumberg, B., Carroll, L., Colborn, T., Everett, L. G., Benbrook, C. M. (2016). Concerns over use of glyphosate-based herbicides and risks associated with exposures: A consensus statement. Environmental Health, 15, 19. https://doi.org/10.1186/s12940-016-0117-0.

Pratt, D. S., \& Kaplan, M. M. (2001). Liver and biliary tract disease, evaluation of liver function. In E. Braunwald, A. Fauci, D. Kasper, S. Hauser, D. L. Longo, \& J. L. Jameson (Eds.), Harrison's principles of internal medicine, (pp. 1711-1714). McGraw-HillProfessional https://accessmedicine.mhmedical.com/Content. aspx?bookld=331\&sectionld=40727097.

Samanta, P., Mukherjeeb, A. K., Palc, S., Kolea, D., \& Ghosha, A. R. (2016). Toxic effects of glyphosate-based herbicide, excel Mera 71 on gill, liver, and kidney of Heteropneustes fossilis under laboratory and field conditions. Journal of Microscopy and Ultrastructure, 4, 147-155. https://doi.org/10.1016/j.jmau.2016. 01.002.

Swanson, N. L., Hoy, J., \& Seneff, S. (2016). Evidence that glyphosate is a causative agent in chronic sub-clinical metabolic acidosis and mitochondrial dysfunction. International Journal of Human Nutrition and Functional, 4, 32 http://intjhumnutrfunctmed.org/journal/2016pdf/IJHNFM_2016_v4q1p9_ GlyphosateMetabolicAcidosisMitochondria.pdf.

Trasher, J. D., Broughton, A., \& Micevich, P. (1988). Antibodies and immune profile of individuals occupationally exposed to formaldehyde: Six case reports. American Journal of Industrial Medicine, 14, 479-488. https://doi.org/10.1002/ ajim.4700140411.

US EPA (U.S. Environmental Protection Agency). (2006). Glyphosate human health risk assessment for proposed use on Indian mulberry and amended use on pea, dry. Memo dated Sept. 29, 2006. 2016. https://archive.epa.gov/ pesticides/chemicalsearch/chemical/foia/web/pdf/103601/103601-2006-0926a.pdf

Vereecken, H. (2005). Mobility and leaching of glyphosate: A review. Pest Management Science, 61(12), 1139-1151. https://doi.org/10.1002/ps.1122.

Vincent, K., \& Davidson, C. (2015). The toxicity of glyphosate alone and glyphosate-surfactant mixtures to western toad (Anaxyrus boreas) tadpoles. Environmental Toxicology and Chemistry, 34(12), 2791-2795. https://doi.org/10. 1002/etc.3118

WHO (World Health Organization). (1994). "Glyphosate. Environmental Health Criteria, 159. Geneva, Switzerland. 177 pp. ISBN 92-4-157159-4:177." from http://www.inchem.org/documents/ehc/ehc/ehc159.htm.

Woods, A., \& Stirling, J. (2008). In J. Bancroft, \& M. Gamble (Eds.), Electron microscope (30) in Theory and practice of HistologicalTechniques, (6th ed., p. 600). Churchill Livingstone: Elsevier.

Wunderlich, F., Dkhil, M. A., Mehnert, L. I., Braun, J. V., El-Khadragy, M., Borsch, E., Krücken, J. (2005). Testosterone responsiveness of spleen and liver in female lymphotoxin beta receptor-deficient mice resistant to blood-stage malaria. Microbes and Infection, 7(3), 399-409. https://doi.org/10.1016/j.micinf.2004.11.016.

Yong, J. C. L. (1997). The mast cell: Origin, morphology, distribution, and function. Experimental and Toxicologic Pathology, 49, 409-424 https://doi.org/10.1051/ parasite/2002094333. 